\title{
A Comparative Clinical Evaluation of Efficacy of Tramadol As An Adjuvant To Bupivacaine En Brachial Plexus Block For Upper Limb Surgery
}

\author{
Regmi NK ${ }^{1}$, Subba $\mathrm{S}^{2}$, Sharma UC
}

\begin{abstract}
Background: In peripheral nerve blocks, adjuvants are added to local anaesthetics to improve the quality of anaesthesia and analgesia. We designed this randomized single blinded prospective study to compare the analgesic efficacy of tramadol used as an adjuvant to bupivacaine for supraclavicular brachial plexus block in patients undergoing orthopaedic surgeries of upper limb. Aim of study: In this study, we aimed to compare onset, duration and quality of analgesia along with respiratory, hemodynamic changes with tramadol as adjuvant to bupivacaine in supraclavicular brachial plexus block in the patients undergoing upper limb surgery. Method: In this prospective randomized control trial, two groups of 30 patients each were investigated. $28 \mathrm{ml}$. of $0.5 \%$ bupivacaine (plain) with $2 \mathrm{ml}$. normal saline was administered in group - I and $28 \mathrm{ml}$. of $0.5 \%$ bupivacaine (plain) with $2 \mathrm{ml}$. (100 mg.) tramadol was administered in group - II. The onset of sensory and motor block, duration of analgesia, respiratory/hemodynamic parameters and post-operatively quality of analgesia via visual analogue scale were assessed. Results: The duration and quality of analgesia was significantly increased by adding tramadol in bupivacaine than bupivacaine alone $(p=<0.001$ and $<0.001)$ whereas there was no statistically significant difference in onset of motor $(p=>0.35)$ and sensory block ( $p=>0.75)$ and also hemodynamic and respiratory parameters. (HR $p=>0.1, \mathrm{MAP} p=>0.5$, and $\mathrm{SPO}_{2} \mathrm{p}=>0.5$ ). Conclusion: The study suggests that tramadol when added to bupivacaine for supraclavicular brachial plexus block enhances the quality of anaesthesia and analgesia without affecting respiratory/hemodynamic parameters.
\end{abstract}

Key words: Bupivacaine, motor block, sensory block, supraclavicular brachial plexus block, tramadol

\section{INTRODUCTION}

William Stewart Halsted first reported the use of cocaine to block upper extremity nerves in 1884 and performed the first brachial plexus block in $1885^{1,2}$. Regional nerve blocks avoid the unwanted effect of anaesthetic drugs used during general anaesthesia and the stress for laryngoscopy and tracheal intubation $^{3}$. It provides complete muscle relaxation, intraoperative haemodynamic stability, effective postoperative analgesia, early ambulation, early resumption of oral feeding, avoids the use of multiple drugs and decreases the stress response. Thus, the incidence of postoperative cardiovascular, pulmonary, gastrointestinal and thromboembolic complications is decreased ${ }^{4,5}$.

The supraclavicular approach to the brachial plexus is an approach above the clavicle. Supraclavicular blocks are indicated for operations on the elbow, forearm and hand. Blockade occurs at the distal trunk-proximal division level ${ }^{6}$.

1. Dr. Nabin Kumar Regmi

2. Dr. Sangeeta Subba

3. Prof. Uttam Chandra Sharma

Address for correspondence:

Dr. Nabin Kumar Regmi

Department of Anaesthesia

Nepalgunj Medical College Teaching Hospital,

Kohalpur, Banke, Nepal

Email: nabinkums@gmail.com
Bupivacaine an amide local anesthetics when compared to other local anesthetic drugs has lesser CNS toxicity but has longer duration of action and increased potency, hence it has been preferred to other local anesthetics for nerve blocks ${ }^{7}$. Tramadol is a synthetic 4-phenyl-piperidine analogue of codeine with mixed $\mu$ opioid and non opioid activity. It also has peripheral local anesthetic properties and in addition to it, when compared to other opioids has less respiratory depressant effect. This led to its use as an additive in peripheral nerve blocks ${ }^{4,8}$. In this study, we aimed to compare onset, duration and quality of analgesia along with respiratory, hemodynamic changes and adverse reactions with tramadol as adjuvant to bupivacaine in supraclavicular brachial plexus block.

\section{MATERIAL AND METHODS}

This was a comparative prospective study conducted from March 2014 to October 2014 in the Department of Anesthesiology, Nepalgunj Medical College Teaching Hospital, Kohalpur after taking approval from the institution review committee. The study was conducted in 60 patient undergoing elective surgeries in their upper single limb. Inclusion criteria were 16 to 60 years patient of either sex scheduled for surgery in single upper limb, patient belonging to ASA grade I and II and giving informed consent. Exclusion criteria were unwilling patient, patient aged below 16 or above 60 years, patient belonging to ASA Grade III, IV and V, infection at the puncture site, documented hypersensitivity to any of the study drugs and patients with any comorbid medical conditions. Patients in 
whom the block effect was partial and required supplementary anesthesia also were excluded.

All patients were admitted to the hospital at least a day before surgery, went a thorough pre-anaesthetic check, familiarisation with Visual Analogue Scale (VAS) and premedcation. Once shifted to operation theatre routine monitoring was done in all patients and were premedicated with midazolam $2 \mathrm{mg}$. intravenously. After proper positioning of the patient and under all aseptic precautions, supraclavicular brachial plexus block was performed by blinded anesthesiologist using subclavian artery as a guide, till paresthesia elicited or sensation of piercing the sheath felt.

Patients were randomly assigned to one of the two groups in a double blind manner for supraclavicular block viz; Group I: 28 $\mathrm{ml}$. of $0.5 \%$ bupivacaine (plain) with $2 \mathrm{ml}$. normal saline (30 cases) and Group II: $28 \mathrm{ml}$ of $0.5 \%$ bupivacaine (plain) with $2 \mathrm{ml}$. (100 mg.) tramadol (30 cases).

Routine monitoring of all the patients including blood pressure, pulse rate, $\mathrm{SpO}_{2}$, electrocardiogram was done. We evaluated onset, quality and duration of sensory and motor block along with side effects if any. Sensory block was assessed with atraumatic pin prick test and motor block with modified Bromage scale. The patient was followed up till $24 \mathrm{hrs}$. postoperatively during which the patient was evaluated for the duration of effective analgesia (time from brachial block to first request of analgesics) and the VAS pain score at that time.

\begin{tabular}{|l|c|c|c|}
\hline Parameters & Group I & Group II & p value \\
\hline Age (Years) & $32.36 \pm 11.10$ & $32.06 \pm 13.03$ & 0.92 \\
\hline Weight (Kg) & $56 \pm 11.29$ & $59.40 \pm 7.81$ & 0.15 \\
\hline Sex (M:F) & $30: 20$ & $35: 15$ & \\
\hline ASA I:II & $28: 2$ & $29: 1$ & \\
\hline
\end{tabular}

Table I: Demographic Profile

\section{VAS Score}

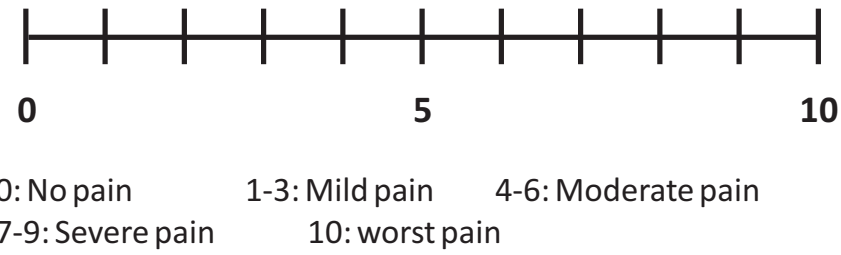

Injection Voveran $75 \mathrm{mg}$. IM as a standard rescue analgesia was given to patient with VRS $>4$. Complication if any was noted.

Statistical Analysis: Statistical test was done using chi square test and student's $t$ test. $P$ value $<0.05$ was considered statistically significant.

\section{RESULTS}

The demographic profile in terms of age, sex, weight, height and ASA physical status were comparable between the two groups. The operative procedures performed were predominantly open reduction and fixation of fracture (ORIF).

\section{Haemodynamic Variables}

The statistical analysis showed that there were no significant differences in heart rate, mean arterial pressure and $\mathrm{SPO}_{2}$ between the two groups ( $p>0.05)$.

\begin{tabular}{|l|c|c|c|}
\hline Parameters & Group I & Group II & p value \\
\hline ORIF & 22 & 23 & 0.90 \\
\hline Implant removal & 4 & 2 & 0.95 \\
\hline Other surgeries & 4 & 5 & 0.60 \\
\hline $\begin{array}{l}\text { Duration of surgery } \\
\text { (mins.) }\end{array}$ & $83.16 \pm 15.61$ & $80.33 \pm 14.31$ & 0.46 \\
\hline
\end{tabular}

Table II: Surgical Profile

\begin{tabular}{|c|c|c|c|c|}
\hline \multirow{2}{*}{$\begin{array}{l}\text { Time of } \\
\text { Assessment }\end{array}$} & \multicolumn{2}{|c|}{ Mean $\pm S D$} & \multirow{2}{*}{$p$ value } & \multirow{2}{*}{ Significance } \\
\hline & Group I (B+NS) & Group II (B+T) & & \\
\hline $0 \mathrm{~min}$ & $76.70 \pm 13.27$ & $81.33 \pm 10.74$ & 0.18 & Ns \\
\hline $15 \mathrm{~min}$ & $75.03 \pm 14.43$ & $81.4 \pm 12.74$ & 0.10 & Ns \\
\hline $30 \mathrm{~min}$ & $73.03 \pm 11.53$ & $78.00 \pm 11.68$ & 0.15 & Ns \\
\hline $45 \min$ & $73.23 \pm 12.52$ & $77.00 \pm 11.43$ & 0.23 & Ns \\
\hline $60 \mathrm{~min}$ & $72.40 \pm 10.40$ & $77.50 \pm 11.72$ & 0.11 & Ns \\
\hline $75 \min$ & $72.20 \pm 11.40$ & $76.50 \pm 11.84$ & 0.19 & Ns \\
\hline $90 \mathrm{~min}$ & $73.83 \pm 10.44$ & $77.86 \pm 10.97$ & 0.16 & Ns \\
\hline Total & 73.8 & 78.5 & $>0.1$ & Ns \\
\hline
\end{tabular}

Table III: Mean Heart Rate (beats/min) among study groups 


\begin{tabular}{|l|c|c|c|c|}
\hline \multirow{2}{*}{$\begin{array}{l}\text { Time of } \\
\text { Assessment }\end{array}$} & \multicolumn{2}{|c|}{ Mean \pm SD } & \multirow{2}{*}{ p value } & \multirow{2}{*}{ Significance } \\
\cline { 2 - 3 } 0 & Group I (B+NS) & Group II (B+T) & & Ns \\
\hline $15 \mathrm{~min}$ & $98.2 \pm 9.05$ & $99.8 \pm 8.09$ & 0.31 & $\mathrm{Ns}$ \\
\hline $30 \mathrm{~min}$ & $97.23 \pm 10.23$ & $99.06 \pm 9.10$ & 0031 & $\mathrm{Ns}$ \\
\hline $45 \mathrm{~min}$ & $96.13 \pm 8.70$ & $97.33 \pm 12.09$ & 0.61 & $\mathrm{Ns}$ \\
\hline $60 \mathrm{~min}$ & $94.03 \pm 9.84$ & $96.06 \pm 12.54$ & 0.51 & $\mathrm{Ns}$ \\
\hline $75 \mathrm{~min}$ & $94.63 \pm 9.54$ & $97.33 \pm 10.78$ & 0.30 & $\mathrm{Ns}$ \\
\hline $90 \mathrm{~min}$ & $94.56 \pm 12.92$ & $96.60 \pm 10.44$ & 0.49 & $\mathrm{Ns}$ \\
\hline Total & $92.63 \pm 10.37$ & $95.93 \pm 9.66$ & 0.18 & $<0.5$ \\
\hline
\end{tabular}

Table IV: Mean arterial pressure ( $\mathrm{mmHg}$ ) among study groups

\begin{tabular}{|c|c|c|c|}
\hline Parameters & Group I & Group II & p value \\
\hline Onset of sensory block & $16.86 \pm 3.67$ & $16.63 \pm 2.70$ & $>0.75$ \\
\hline Onset of motor block & $23.10 \pm 4.34$ & $22.16 \pm 3.14$ & $>0.35$ \\
\hline Duration of Analgesia & $264 \pm 64.10$ & $456 \pm 64.19$ & $<0.001$ \\
\hline VAS Score & $6.93 \pm 1.22$ & $4.66 \pm 1.12$ & $<0.001$ \\
\hline
\end{tabular}

Table V: Sensory and motor block profile

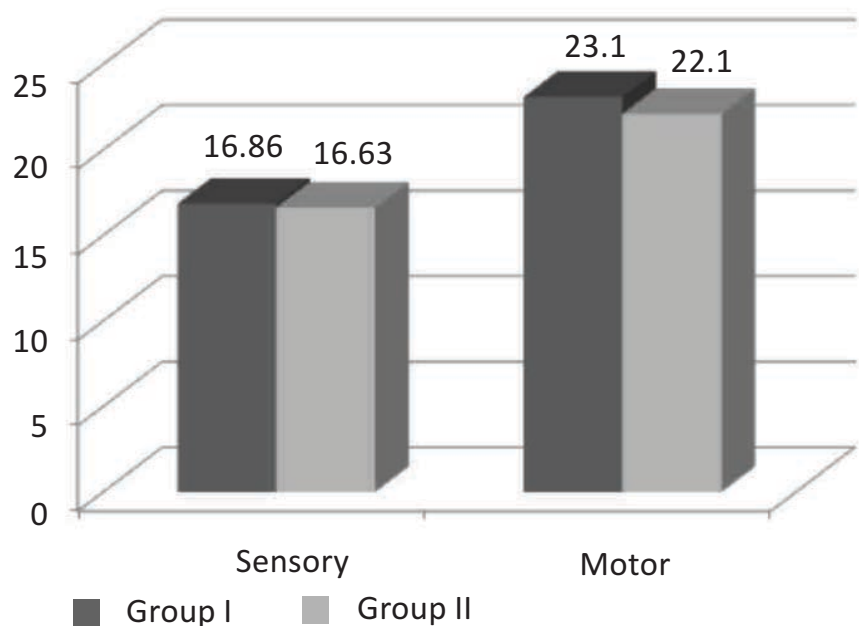

Figure 1: Comparison of onset of block (mins.) among groups

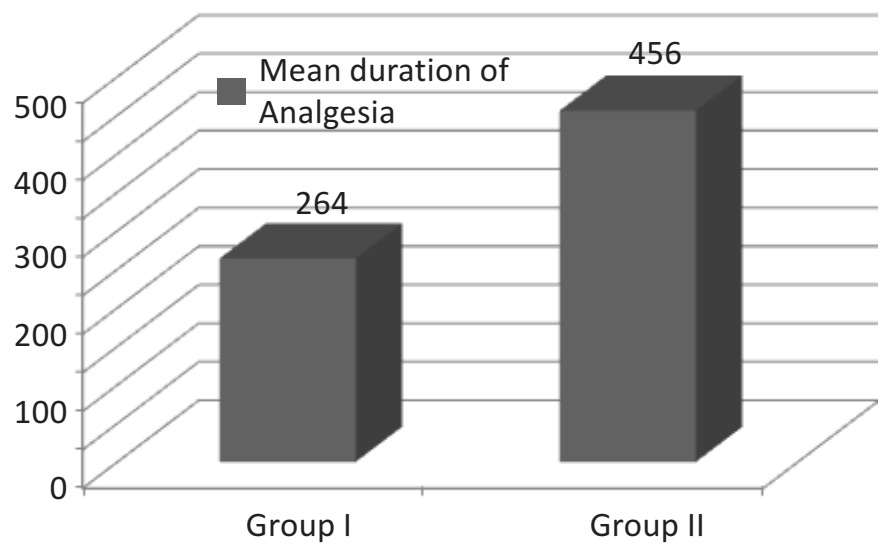

Figure 2: Comparison of mean duration of analgesia

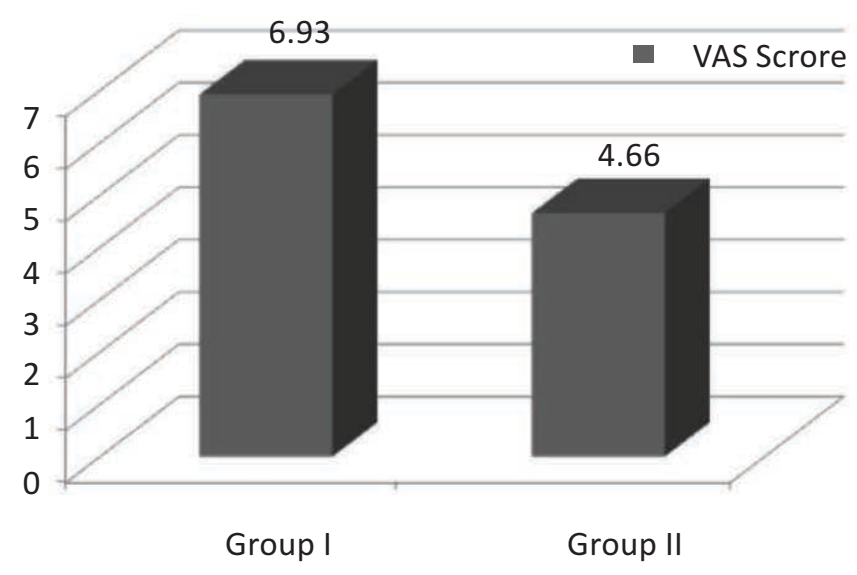

Figure 3: Comparison of VAS among the groups

\section{OXYGEN SATURATION}

In Group I the mean oxygen saturation ranged from $98.00 \pm 0.64$ to $98.3 \pm 0.79$. In Group II the mean oxygen saturation ranged from $98.03 \pm 0.71$ to $98.3 \pm 0.65 \mathrm{~mm}$ of $\mathrm{Hg}$. The statistical analysis showed that there were no significant differences in oxygen saturation between two groups ( $p>0.5)$.

\section{DISCUSSION}

Brachial plexus block provides a useful alternative to general anesthesia for upper limb surgeries as they achieve ideal operating conditions by producing complete muscular relaxation maintaining stable intraoperative hemodyanamics and the associated sympathetic block ${ }^{9}$. Supraclavicular brachial 
plexus block provide anesthesia to the entire upper extremity in the most consistent manner of any brachial plexus techniques. Local anesthetics are used for this purpose. Currently available local anesthetics can provide analgesia for limited period of time when used an single injection. To extend the analgesia period beyond the operation room various methods have been tried with the aim of prolonging the local anesthetic action, like continuous infusion of local anesthetic via indwelling catheters, use of different additive in local anesthetics ${ }^{2}$.

Opioids are commonly used as adjuvants with local anesthetics in brachial plexus block. When the mixture is injected, opioids produce analgesia by specifically binding and activating the opiate receptors in the substantia gelatinosa, whereas local anaesthetics provide analgesia by blocking impulse transmission at the nerve roots and dorsal root ganglia ${ }^{10}$. In addition to this advantage of opioids recent studies have concluded that tramadol displays a peripheral local anesthetic effect $^{11,12}$. Moreover it also lacks respiratory depressant effects unlike other opioids ${ }^{4}$. Hence an attempt has been made to ascess the efficacy of Tramadol as an adjuvant to Bupivacaine in supraclavicular Brachial Plexus block in terms of onset, duration and quality of analgesia.

In this study, it has been found that the total duration of analgesia following brachial plexus block in Group II (bupivacaine +tramadol) was significantly higher than in Group I (bupivacaine + normal saline). This result is similar to the result of the study done by Antonucci ${ }^{13}$, Madhusudhana et $\mathrm{al}^{14}$, Shah et al $^{9}$ and Nagpal et al $^{15}$ but different from Sarsu et al $^{16}$ where the duration of analgesia was not prolonged.

Intensity of postoperative pain was evaluated using VAS. This study, similar to the study done by Madhusudhana et $\mathrm{al}^{14}$ showed there is a significant decrease in VAS (intensity of pain) postoperatively when tramadol is added to local anesthetics during supraclavicular block.

In this study, no significant difference was seen between the onset of motor and sensory blockade between the two groups. Kapral $\mathrm{S}^{17}$, et al also noted that tramadol doesn't have influence on onset of anesthesia.

In this study, there was no significant difference in the hemodyanamics parameters (Heart Rate, Blood Pressure and $\mathrm{SPO}_{2}$ ) between the two groups peri-operatively. Same observations were noted by Kapral $\mathrm{S}^{17}$ and Shah et al $^{9}$.

\section{CONCLUSION}

The addition of $100 \mathrm{mg}$ of tramadol to $28 \mathrm{ml}$ of $0.5 \%$ bupivacaine for supraclavicular brachial plexus block significantly prolongs the total duration of analgesia, decreases the in t e n s ity of postoperative pain without any effect on onset of sensory block and motor block. The hemodynamic parameters do not alter by addition of tramadol.

\section{REFERENCES}

1. Hall RJ. Hydrochlorate of cocaine. NY Med J. 1884;40:643-6.

2. Halsted WS. Practical comments on the use and abuse of cocaine; suggested by its invariably successful employment in more than a thousand minor surgical operations. NY Med J. 1885; 42:294.

3. Shrestha BR, Maharjan SK, Shrestha S, Gautam B, Thapa C, Thapa $\mathrm{PB}$ et al. Comparative study between tramadol and dexamethasone as an admixture to bupivacaine in supraclavicular brachial plexus block. J Nepal Med Assoc. 2007;46(168):158-64.

4. Shaikh SI, Veena K. Midazolam as an adjuvant in supraclavicular brachial plexus block. Anaesth Pain \& Intensive Care 2012;16(1):7-11.

5. Rathod H, Parikh H, Upadhayaya RM. Comparative study of $0.375 \%$ bupivacaine and $0.375 \%$ ropivacaine in brachial plexus block via supraclavicular approach. IJBR 2015; 6(02):77-82.

6. Laiq N, Khan MN, Arif M, khan S. Midazolam with bupivacaine for Improving analgesia quality in brachial plexus block for upper limb surgeries. J Coll Physicians Surg Pak. 2008;18(11):674-8.

7. Wiles MD, Nathanson MH. Local anaesthetics and adjuvants future developments. Anaesthesia. 2010;65:22-37.

8. Robaux S, Blunt C, Viel E, Couvillan P, Nouguier P, Dautel G, et al. Tramadol added to $1.5 \%$ mepivacaine for axillary brachial plexus block improves postoperative analgesia dose-dependently. Anesth Analg. 2004;98:1172-7.

9. Shah RB, Arora G. Comparison of tramadol and clonidine as an adjuvant in brachial plexus block. Anaesthesia. 2014; 49(10):1-3.

10. Christiansson L. Update on adjuvants in regional anaesthesia. Periodicum Biologorum. 2009;111(2):161-70.

11. Stoelting RK, Hillier SC. Opioids. Pharmacology and Physiology in Anesthetic Practice. $4^{\text {th }}$ ed. Philadelphia: Lippincott Williams and Wilkins; 2006.p.198-9.

12. Fukuda K. Opioids. In: Miller RD, Eriksson LI, Fleisher LA, editors. Miller's Anesthesia. $7^{\text {th }}$ ed. USA: Churchill Livingstone; 2010.p.769-824.

13. Antonucci S. Adjuvants in the axillary brachial plexus blockade: comparison between clonidine, sufentanil and tramadol. Minerva Anestesiologica. 2001;67:23-7.

14. Madhusudhana R, Kumar K, Kumar R, Potli S, Karthik D, Kapil M, et al. Supraclavicular brachial plexus block with $0.75 \%$ ropivaciane and with additives tramadol, fentanyl- a comparative pilot study. Int J Biol Med Res. 2011;2(4):1061-3.

15. Nagpal V, Rana S, Singh J, Chaudhary Sk. Comparative study of systemically and perineurally administered tramadol as an adjunct for supraclavicular brachial plexus block. J Anaesthesiol Clin Pharmacol. 2015; 31(2): 191-5.

16. Sarsu S, Mizrak A, Karakurum G. Tramadol use for axillary brachial plexus blockade. J Surg Res 2011;165:23-7.

17. Kapral S, Gollmann G, Waltl B et al., "Tramadol added to mepivacaine prolongs the duration of an axillary brachial plexus blockade," Anesthesia \& Analgesia. 199;88(4),:853-6. 